\title{
A relationship between all Atlantic hurricanes and those that make landfall in the USA
}

\author{
K. Coughlin, ${ }^{a *}$ E. Bellone, ${ }^{a}$ T. Laepple, ${ }^{b}$ S. Jewson ${ }^{a}$ and K. Nzerem ${ }^{a}$ \\ ${ }^{a}$ Risk Management Solutions Limited, London \\ ${ }^{\mathrm{b}}$ Alfred Wegener Institute for Polar and Marine Research, Bremerhaven, Germany
}

\begin{abstract}
The interannual prediction of the number of hurricanes to strike the US coastline is of vital interest to those who live on the coast, those who insure property along the coast and policy makers who make decisions about infrastructure and mitigation measures. Here it is shown that these predictions can be made more accurate when information about the total number of Atlantic Basin hurricanes is considered. The proportion of Atlantic hurricanes that make landfall in the USA is a measure of the relationship between landfalling and basin hurricane numbers. In order to use basin numbers to help make predictions of landfalling numbers, we must first investigate the nature of this relationship. Here we run a number of statistical tests and find that there is a significant change in the relative proportion of Atlantic hurricanes that hit the US coastline between the first and second halves of the 20th century. This difference is ostensibly due to the lack of basin observations in the earlier period. However, after 1948, the proportion of Atlantic hurricanes that hit the US coast shows no evidence of change. By assuming that the proportion is constant, we are able to then use information about the total number of hurricanes in the Atlantic Basin and make more accurate estimates of landfalling hurricane activity. Copyright (C) 2009 Royal Meteorological Society
\end{abstract}

KEY WORDS hurricanes; predictions

Received 11 August 2008; Revised 4 December 2008; Accepted 9 December 2008

\section{Introduction}

Hurricanes have a severe impact on coastal communities in the USA, and many of these communities are concerned about the recent increase in the number of Atlantic hurricanes. There is also a lively debate and much interest in the scientific community as to what is causing this increase and whether it will continue in the future (Trenberth, 2005; Landsea et al., 2006; Mann and Emanuel, 2006; Bell et al., 2007; Vecchi and Soden, 2007).

Work by Webster et al. (2005), Hoyos et al. (2006) and Mann and Emanuel (2006) suggests that, in the Atlantic, there is an increasing trend in the frequency and intensity of hurricanes, in part due to the rise in sea-surface temperatures (SSTs) brought on by global warming. Trenberth (2005), however, suggests that although increasing SSTs are likely to increase intensity and rainfall from hurricanes, the effect of increasing SSTs on hurricane numbers is unclear. Dynamical climate models have been used to estimate the impact of global warming on hurricane intensity and precipitation (Knutson and Tuleya, 1999, 2004; Bengtsson et al., 2007; Emanuel et al., 2008; Knutson et al., 2008). These models show a $\mathrm{CO}_{2}$-induced increase in storm intensity $(5-7 \%$ increase in maximum wind speeds) and rainfall (12-26\% increase in the precipitation rate within $100 \mathrm{~km}$ of the storm centre) and mixed

\footnotetext{
*Correspondence to: K. Coughlin, Risk Management Solutions Limited, Peninsular House, London, EC3R 8NB, UK

E-mail: katie.coughlin@rms.com
}

results in storm frequency $(+2.2 \%$ to $-25 \%$ change in tropical cyclone frequency and $+40 \%$ to $-18 \%$ change in the number of Atlantic hurricanes) over the next century. Further studies by Klotzbach (2006) and Goldenberg et al. (2001) suggest that changes in long-term Atlantic hurricane activity are more influenced by natural variability, such as the Atlantic Multidecadal Oscillation (AMO), than by anthropogenic changes. In addition to the internal variability of the AMO and the SST rise due to global warming, other climatic features that vary on faster time-scales, such as the North Atlantic Oscillation (NAO) (Elsner et al., 2000), the quasi-biennial oscillation (QBO) (Shapiro, 1982; Gray, 1984), the El Niño Southern Oscillation (ENSO) (Bove et al., 1998; Camargo and Sobel, 2005) and circulation changes over the Atlantic (Zehr, 1992; DeMaria et al., 1993; Landsea, 1998) have also been shown to be related to hurricane activity.

Because the variation in hurricane activity over different time-scales depends on different mechanisms, the methodology used to make predictions will vary according to the forecast period of interest. Our particular interest is driven by the needs of the insurance and re-insurance industry and we are interested in making reliable five-year predictions of the number of Atlantic hurricanes that make landfall in the USA.

We, however, have more information about hurricanes in the entire Atlantic basin than we do about only those hurricanes that hit the US coast. In particular, there is a larger number of basin hurricanes so the statistics 
associated with them will be more robust and we can therefore detect signals more accurately. Also, there is a better understanding of how the environment influences hurricanes over the ocean (Gray, 1979; Emanuel, 1986, 1995; Goldenberg and Shapiro, 1996; Goldenberg et al., 2001). How then can we use this information to help predict the number of landfalling hurricanes? Perhaps on the surface there seems little reason to think of the landfalling storms as anything other than a random sample of the basin storms that happen to hit the edge of the basin (i.e. make landfall). In this case, then, the underlying mean number of landfalls could be represented purely as a constant fraction of the total number of Atlantic hurricanes. However, if we delve deeper into the issue and look at individual storms it is clear that environmental factors influence where the Atlantic storms go and hence the steering of any particular storm towards land (Bove et al., 1998; Camargo and Sobel, 2005). What is less understood is whether these environmental factors should be treated as noise on interannual timescales or whether the probability of landfall varies in concert with the interannual basin activity such that there is no consistent relationship between the number of basin and landfalling storms. If, however, there is a consistent relationship between the two, then we can use the basin information to help us make predictions about the numbers of storms that make landfall.

In this article, we aim to answer a sequence of questions in order to determine whether or not the basin information is useful for making five-year predictions of the number of landfalling storms. First, in section 3, we run a number of simple statistical tests to determine whether the proportion of Atlantic storms that hit the US coast varies with activity in the basin. From these tests we find that since 1948, when aircraft monitoring covered the Atlantic, there is no evidence of a change in the proportion associated with the changing activity in the basin. In section 4, we then look more generally for any change in the proportion since 1948 regardless of the basin activity. In this study, a Monte Carlo experiment shows that the observed data are consistent with the assumption of a constant proportion since 1948. These results lead to an interesting contradiction because previous work has shown that there are significant changes in the number of hurricanes in the basin but no detectable changes in the mean number of landfalling hurricanes. If the basin storm activity varies but the landfalling activity does not, then we might assume that the proportion should vary with the basin activity. This apparent contradiction is explored in section 5 . Essentially, changes in both the landfalling numbers and changes in the proportion are not detected because landfalling hurricanes are relatively rare, making the signal-to-noise ratio in both cases too low for detection. We do, however, find that changes in the proportion should be easier to detect than changes in the landfall activity.

Given the evidence in sections 3-5, we cannot detect any significant changes in the relationship between the number of hurricanes in the basin and the number that make landfall on interannual time-scales. This means that if the proportion of landfalling storms does vary, and it is unlikely that the proportion is exactly constant, the changes are too small to detect and therefore too small to measure accurately. Section 6 then asks the question whether this information is useful. An out-of-sample hindcast experiment shows that when we use the basin information and a constant relationship between basin and landfall numbers to predict the historical number of landfalls, we make more accurate predictions than when we use only landfalling information.

\section{Data}

All the tests and analysis in this article use the Atlantic basin hurricane database (HURDAT) record of landfalling category 1-5 hurricanes up to 2007 (Jarrell et al., 1992). The number of Atlantic basin category 1-5 hurricanes provided by HURDAT (Jarvinen et al. 1984 and updates from HURDAT (http://www.aoml.noaa.gov/hrd/hurdat/Data_Storm.html)) are also used up to and including the year 2007. The total number of landfalling hurricanes in the USA used here includes a number of bypassing storms where the storm centre did not cross the US coast but where hurricane force winds from the storm occurred in the USA. The quality of the observations of hurricanes in the North Atlantic has improved over time with the development of new technologies such as aircraft reconnaissance and satellite-based remote sensing. Therefore it is likely that Atlantic hurricanes that did not make landfall were undercounted, especially in the earlier half of the record (Landsea, 2007). This would result in a larger proportion of observed hurricanes making landfall during these years. A number of authors (Solow and Moore, 2002; Landsea, 2007; Vecchi and Knutson, 2008) have made corrections to the past record in order to rectify this bias. In this study we use only the HURDAT record from 1900-2007, but we do discuss the observational bias in the early record where appropriate.

\section{Question 1: does the proportion vary with hurri- cane activity?}

We first consider whether or not the proportion of hurricanes hitting the US coast changes relative to changing activity in the basin. A number of studies (including Elsner et al., 2000; Goldenberg et al., 2001; Jewson and Penzer, 2006) have shown that the mean number of hurricanes in the Atlantic basin is not stationary and have proposed that the evolution of activity can be determined by dividing the historical record into periods that each have a constant underlying rate. The change in the proportion of landfalling hurricanes across these different periods of activity is investigated by testing three null hypotheses that differentiate between the earlier and later parts of the whole time interval, as well as using pairwise tests over all combinations of the different periods. 
It is noted that the latter results are especially affected by a multiple comparison problem and are only shown for completeness. Commonly used tests of equality of proportions include the chi-square test and the $G$-test, both of which involve chi-square approximations. The results reported in Table II are obtained using a standard chisquare test; $p$-values of the $G$-test (not reported here) are very similar and lead to the same conclusions. The time periods that we are testing are long enough that there are enough expected landfalls during these periods for the chi-square or $G$-test to be good approximations to an exact test, such as Fisher's.

The main hypothesis of interest is that the underlying proportion of hurricanes making landfall is constant since about 1950. Motivated by the potential observational issues of the earlier basin data, we also look for differences between the earlier and later parts of the record.

All statistical tests use the set of change points detected by both Elsner (2000) and Jewson and Penzer (2006). These change points determine when the basin activity shifts from one period of activity to another. The analysis described in Elsner (2000) gives change points in 19421943, 1964-1965 and 1994-1995. The analysis described in Jewson and Penzer (2006) gives change points in 1931/1932, 1947-1948, 1969-1970 and 1994-1995. We analyse both sets in order to understand the sensitivity of the results to using alternative sets of change points. Estimates of the proportion of Atlantic hurricanes that hit the USA for each period, and their associated standard errors, are shown in Table I. The standard error calculation (a standard formula as found in Box et al. 1978) does not take the variability of the basin numbers into consideration. When the variation of the basin numbers is accounted for, as in section 5, the standard errors are larger than those shown in Table I.

For the Elsner (2000) change points we test the following hypotheses.

- The underlying proportions in the four periods defined by these change points are constant.

- The underlying proportions in the last three periods defined by these change points are constant.

- The proportion before 1943 (the first change point) is the same as the proportion after 1943.

For the Jewson and Penzer (2006) change points we test the corresponding hypotheses:

- The underlying proportions in the five periods defined by these change points are constant.

- The underlying proportions in the last three periods defined by these change points are constant.

- The proportion before 1948 (the second change point) is the same as the proportion after 1948.

The results of these tests are shown in Table II. For both sets of change points, using a significance level of 0.05 , the hypothesis that the proportion has remained constant since 1900 is rejected, but we cannot reject the hypothesis that the proportion has remained constant in the second half of the century.

From this we conclude that the proportion of landfalling storms during the first half of the century is different from the proportion in the later periods, but that the underlying proportion of landfalling storms in the periods since at least 1948 may well be the same. One possible

Table I. Estimates of the proportion of storms making landfall, based on periods defined by the change points identified in Elsner (2000) and Jewson and Penzer (2006).

\begin{tabular}{lccc}
\hline Elsner period & Estimated proportion & $\begin{array}{c}\text { Jewson and Penzer } \\
\text { period }\end{array}$ & Estimated proportion \\
\hline $1900-2007$ & 0.33 & $1900-2007$ & 0.33 \\
& & $1900-1931$ & $0.46 \pm 0.05$ \\
$1900-1942$ & $0.46 \pm 0.04$ & $1932-1947$ & $0.45 \pm 0.06$ \\
$1943-1964$ & $0.33 \pm 0.04$ & $1948-1969$ & $0.28 \pm 0.04$ \\
$1965-1994$ & $0.24 \pm 0.03$ & $1970-1994$ & $0.25 \pm 0.04$ \\
$1995-2007$ & $0.24 \pm 0.04$ & $1995-2007$ & $0.24 \pm 0.04$ \\
\hline
\end{tabular}

Table II. Results of chi-square hypothesis tests, indicating that there is no change in the proportion of Atlantic storms that make landfall in the last half of the century.

\begin{tabular}{llr}
\hline Hypothesis & Result & $p$-value \\
\hline Elsner: 4 proportions are equal & Rejected & $<0.01$ \\
Elsner: proportions after 1943 are equal & Accepted & 0.16 \\
Elsner: proportions before and after 1943 are equal & Rejected & $<0.01$ \\
Jewson: 5 proportions are equal & Rejected & $<0.01$ \\
Jewson: proportions after 1948 are equal & Accepted & 0.71 \\
Jewson: proportions before and after 1948 are equal & Rejected & $<0.01$ \\
\hline
\end{tabular}


Table III. $P$-values from the pairwise comparison of both Elsner and Jewson and Penzer change points.

\begin{tabular}{lcccc}
\hline Elsner CP & $1943-1964$ & $1965-1994$ & $1995-2007$ & \\
$1900-1942$ & 0.03 & $<0.01$ & $<0.01$ & \\
$1943-1964$ & & 0.09 & 0.12 & \\
$1965-1994$ & & & 0.95 & \\
& & & & \\
Jewson CP & $1932-1947$ & $1948-1969$ & $1970-1994$ & $1995-2007$ \\
$1900-1931$ & 0.87 & $<0.01$ & $<0.01$ & $<0.01$ \\
$1932-1947$ & & 0.01 & $<0.01$ & $<0.01$ \\
$1948-1969$ & & & 0.57 & 0.44 \\
$1970-1994$ & & & & 0.81 \\
\hline
\end{tabular}

explanation is certainly that the number of basin hurricanes counted during the first period is inaccurate. There is strong evidence for different landfalling proportions in the earlier part of the data, but no evidence of changes in those proportions in the later part of the data.

To corroborate these results, we look at the chisquare pairwise comparisons for all combinations of the activity periods defined by both Elsner (2000) and Jewson and Penzer (2006). This is less satisfactory than the concurrent tests given above, since it involves a large number of comparisons, and we do not try to calculate the influence of our multiple testing directly but take this into consideration when interpreting the results.

The $p$-values from the pairwise comparisons for the periods defined by both sets of change points are shown in Table III. Once again the results indicate that the probabilities in the earlier data are different from those in the later periods, but there is no significant variation within the proportions of the later periods.

\section{Question 2: can we detect any variations in the proportion?}

The first study shows that the proportion of landfalling storms during active periods is not statistically different from the proportion during inactive periods. This next study asks whether or not we can detect changes in the proportion that are perhaps independent of change-point analysis.

We compare the observed annual and five-year mean landfall proportions with Monte Carlo simulations of the landfalls generated from the observed basin numbers with a probability of landfall that is constant. The constant landfall probability is equal to the mean landfall proportion since 1948, and the synthetic annual landfall numbers are simulated by drawing from a binomial distribution with $n$ equal to the annual basin number and $p$ equal to the long-term landfall probability. Confidence intervals for the observed proportion are constructed from the $2.5 \%$ and $97.5 \%$ quantiles of the simulated landfall ratios.

In Figure 1, we show the observed proportion of hurricanes that made landfall in the USA from 1948 to 2007. By comparing the actual proportions with the

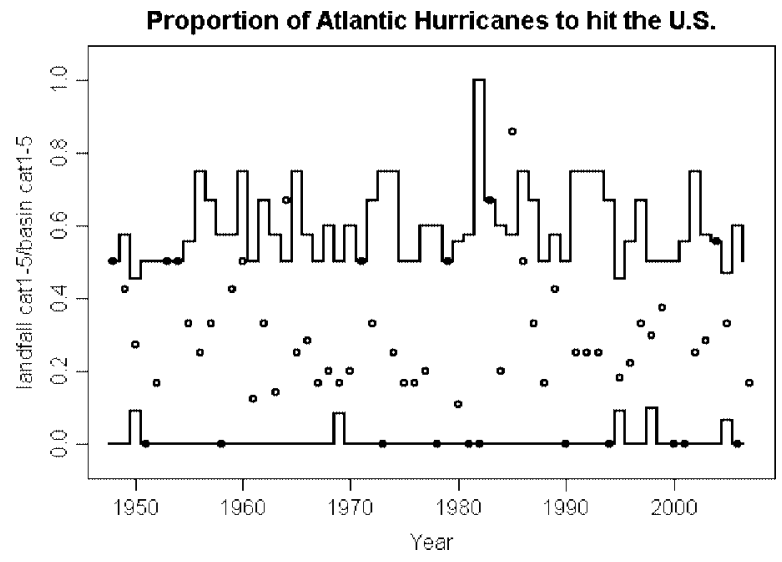

Figure 1. Proportion of Atlantic hurricanes that make landfall in the USA from 1948-2007. The figure includes Monte Carlo simulated 95\% confidence intervals.

confidence interval from the synthetic data, it is obvious that large year-to-year variability is possible and expected even under the assumption that the underlying proportion remains constant. We see that two out of the 60 years give values outside the confidence limits, which implies that $97 \%$ of the yearly proportions are within the confidence intervals, giving no reason to doubt the assumption that the probability is constant.

In Figure 2, we show the observed proportion of landfalling hurricanes estimated using five-year averages from 1948 onwards, along with the associated 95\% confidence intervals. Yet again, there is no evidence that the probability of making landfall varies in time. We shift our five-year averages by one, two, three and four years in order to cover all combinations and our conclusion remains the same; there is no evidence that the proportion of hurricanes making landfall changes in time.

\section{Question 3: how do we rectify the apparent con- tradiction between constant proportion and constant landfall mean?}

The results from the previous sections show that we cannot detect any change in the proportion of landfalling hurricanes. However, this seems to contradict previous results found in Nzerem et al. (2006) where the authors assume that the number of Atlantic basin hurricanes and 

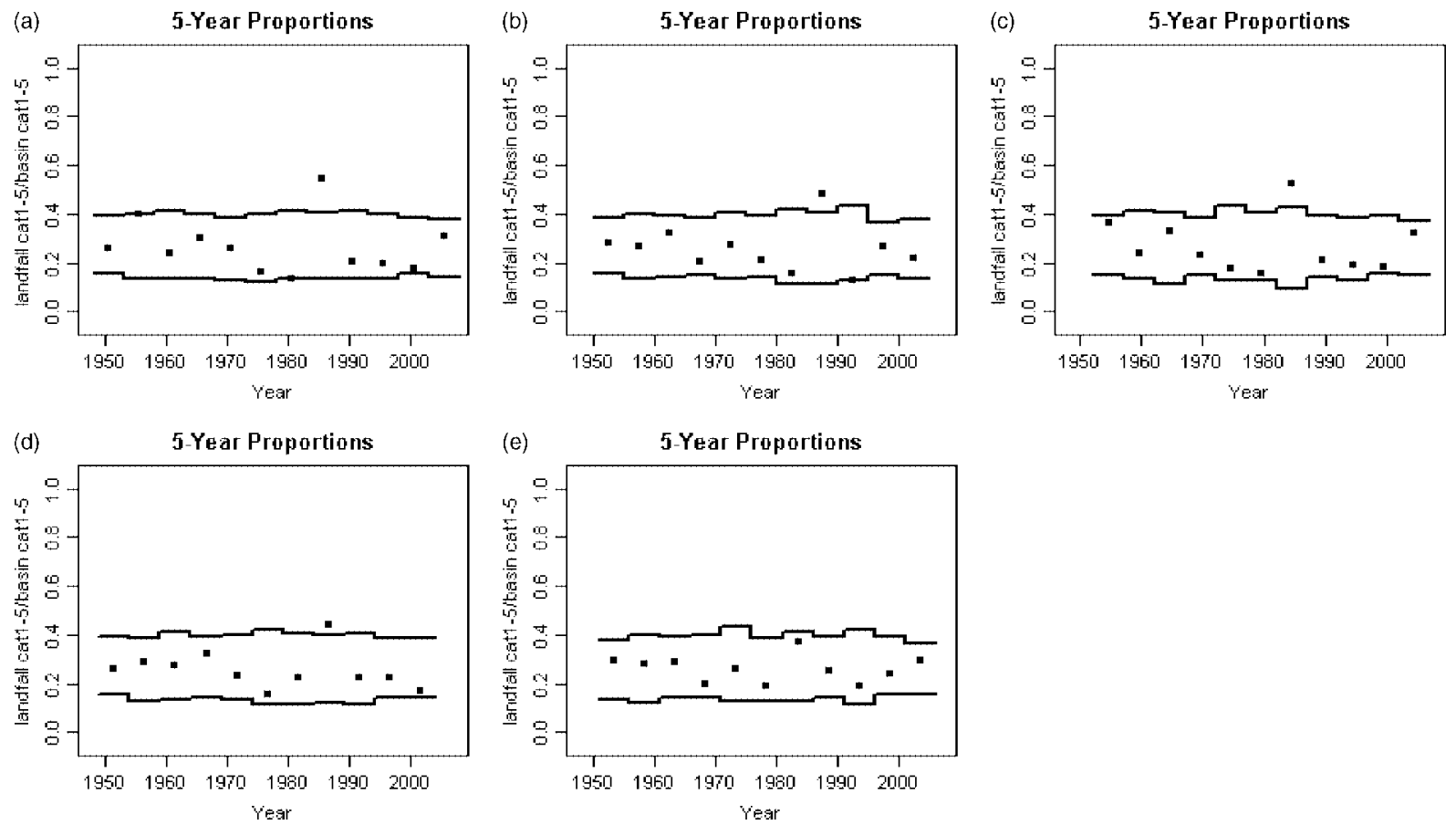

Figure 2. Five-year averages of the proportion of Atlantic hurricanes that make landfall. The plots begin in 1948, 1949, 1950,1951 and 1952 in order to cover all combinations of 5-year periods and the figures include $95 \%$ confidence intervals.

the number of US landfalls follow Poisson distributions and they show that, while there are detectable changes in the mean number of Atlantic basin hurricanes, similar changes could not be detected in the mean landfalling numbers. Combining these results with the results from the previous section, we know that the basin numbers are changing and yet we see no changes in either the landfalling numbers or the proportion of landfalling hurricanes. Therein lies an apparent contradiction. If the landfalling numbers are constant, then should we not expect to see a change in the proportion? If the proportion is really constant, then should we not expect to see a change in the landfalling numbers? In reality, both the number of landfalling hurricanes and the proportion of Atlantic hurricanes that hits the USA may be changing, but the scarcity of US landfalls means that these changes may be obscured by noise. Nzerem et al. (2006) explain that owing to the small number of landfalling hurricanes we would not expect to detect a change in the number of landfalls, even in experiments where we know there is a change. This is because, for Poisson processes, the signal-to-noise ratio decreases as the mean number of counts decreases. For the case of Atlantic hurricanes, the decrease in signal, theoretically about a factor of 4 when we go from detection in the basin to detection at landfall, means that the landfall signal is lost in the noise.

We perform two simple experiments similar to the ones in Nzerem et al. (2006). Unlike the previous sections, these experiments explicitly take into consideration the variability of the basin numbers as well as variability in the number of landfalls. First we assume that the landfall proportion is constant and we simulate landfalls for 100000 replicates of the 1948-2007 period. The basin numbers are generated using a Poisson distribution with mean equal to the observed mean number of basin hurricanes during active and inactive periods. Using Jewson and Penzer's change points, the Poisson means for the active periods are taken to be the 1948-1969 and 1995-2007 mean respectively, while the mean for the inactive periods is taken from the years 1970-1994. The number of landfalls is drawn from a binomial distribution where the number of trials is equal to the total number of hurricanes in the basin, and the probability of success equals the estimated proportion for the whole 19482007 interval. A chi-square test with $p$-value of 0.05 or smaller is used to detect changes in the landfalling levels between periods within each simulation. From this experiment, where we know that the underlying means of the generated landfalling numbers are changing from one period to the next, we find that we can only actually detect the first change point $20 \%$ of the time, the second change point $44 \%$ of the time; in $14 \%$ of the simulations we detect both changes. Note that when the landfalling numbers are chosen from the actual number of hurricanes in the basin the results do not change qualitatively. In most of the simulations we cannot detect the change, even though we know it is there, because the year-toyear variability is large compared with the change in the underlying mean landfalling rate that we are interested in detecting. These are type II errors (false negative results). The probability of not detecting a change even when there is a change in the landfalling numbers is shown in Table IV. This experiment shows that there is over a $50 \%$ chance that we would not detect changes in the landfalling numbers, even if they were present.

In a complimentary experiment, we assume that the landfalling numbers have an underlying constant mean and perform the same experiment as above except that 
now the probability of landfall changes from one period to the next. The changing probability is calculated by taking the annual mean number of landfalls from 1948-2007 and dividing by the mean number of basin hurricanes for each period. Now the underlying mean number of landfalls is constant and the proportion varies from one period to the next. Using a chi-square test with a significance level of 0.05 , we detect the change in proportions $30 \%$ of the time between the first active period and the inactive period, $53 \%$ of the time between the inactive period and the last active period; in $23 \%$ of the simulations, both changes are detected. Again the detection rates are very similar when the landfalls are picked from the actual number of basin hurricanes each year. Although the probability of a type II error is large, the probability of a false negative result is smaller for the detection of a change in the proportions than for the detection of a change in the landfalling numbers (see table IV). These results confirm that, even under different basin activity levels, it is likely that chi-square tests will not detect changes in either the observed landfalling means or the observed proportions. Additionally, the simulations suggest that it is easier to detect changes in the proportion than changes in mean landfalling numbers.

In both of these experiments, there are many type II errors, and this may explain why we cannot detect these variations in the observed data. The fact that we expect estimates of the proportion to be more accurate than estimates of the landfalling numbers is due to the relative signal-to-noise ratio for the landfalling numbers compared with that of the proportions. The signal-tonoise ratio is defined as

$$
S N R=\frac{|A|^{2}}{|N|^{2}},
$$

which is the squared amplitude of the signal divided by the squared amplitude of the noise. This ratio compares the level of the signal with the amount of noise obstructing the signal. For the landfalling numbers we estimate the signal for each activity period as the annual mean number of landfalls per period and the noise as the standard deviation around this signal. The signal in the

Table IV. The probability of not detecting a change when there is an underlying change in the data (type II error). These probabilities are shown for two experiments: one where the underlying landfall numbers are changing and another where the underlying proportion changes in accord with the observed basin change points. The probability of a type II error occurring is shown for the first change point (1969-1970), the second change point (1994-1995) and for the detection of both change points.

\begin{tabular}{lccc}
\hline Probability of type II error & & & \\
\hline & $1969-1970$ & $1994-1995$ & Both \\
$\begin{array}{l}\text { Changing landfall numbers } \\
\text { numbers }\end{array}$ & $80 \%$ & $56 \%$ & $86 \%$ \\
Changing proportions & $70 \%$ & $47 \%$ & $79 \%$ \\
\hline
\end{tabular}

Table V. Signal-to-noise ratios for the last three activity periods.

\begin{tabular}{cccc}
\hline & Basin & Landfall & Proportion \\
\hline $1948-1969$ & 8.07 & 2.38 & 2.79 \\
$1970-1994$ & 8.34 & 0.91 & 1.35 \\
$1995-2007$ & 6.40 & 1.27 & 2.33 \\
\hline
\end{tabular}

proportion of each period is estimated as the total number of landfalling hurricanes divided by the total number of basin hurricanes over the period and the noise is the standard deviation of yearly proportions around this signal. We show the SNR for Jewson and Penzer's last three periods in Table $\mathrm{V}$.

Table $\mathrm{V}$ shows that while we can detect changes in the basin numbers, because the signal-to-noise ratio of the basin numbers is relatively high, signals in both the landfall numbers and the proportions may be difficult to detect because the signal-to-noise ratios are relatively low. These results agree with the results in Nzerem et al. (2006). In support of the previous Monte Carlo tests, the table also shows that the proportion of landfalling hurricanes has a higher signal-to-noise ratio than the landfall numbers themselves. So, in practice, we should be able to estimate the proportion of landfalls more accurately than the landfalling numbers. The results for Elsner's change-point periods lead to the same conclusions.

\section{Question 4: can we use this information to make better interannual predictions?}

To answer this question let us review what we know and consider the various possibilities. To begin with, we know that landfalling hurricanes are a subset of basin hurricanes and we know that the basin numbers contain significant change points (Elsner, 2000; Jewson and Penzer, 2006). We have not, however, been able to show that either the landfall numbers or the proportion of landfalls contain significant change points, presumably because there are fewer events and the noise obscures the signal, as shown in the last section and in Nzerem et al. (2006).

Given the change points in the basin, there are three possible underlying assumptions that lead to estimates of the proportion of basin hurricanes that ultimately make landfall.

(1) The landfall numbers are constant and the proportion reflects changes in the basin numbers.

(2) The landfall numbers change with the basin numbers and the proportion remains constant.

(3) The landfall numbers change independently of the basin numbers and all three - the basin numbers, the landfalling numbers and the proportion - vary over time.

Again, in all likelihood, the third scenario may be technically true for individual events, but we are interested in multi-year predictability and ultimately we would like to 
know which scenario is most useful for our purpose of making five-year predictions.

Considering the 1994-1995 change point (Elsner, 2000; Jewson and Penzer, 2006), these three scenarios can be represented by the following definitions of landfalling proportions during the last active and inactive periods:

(1) $p_{1}=L_{0} / B_{1}$ and $p_{2}=L_{0} / B_{2}$,

(2) $p_{1}=L_{0} / B_{0}$ and $p_{2}=L_{0} / B_{0}$,

(3) $p_{1}=L_{1} / B_{1}$ and $p_{2}=L_{2} / B_{2}$,

where $L_{0}$ and $B_{0}$ are the landfall and basin rates for the period 1970-2007 (i.e. over the two intervals on either side of the 1994-1995 change point). $L_{1}$ and $B_{1}$ are the landfall and basin rates for the period 1970-1994 (the first interval) and $L_{2}$ and $B_{2}$ are the landfall and basin rates for the period 1995-2007 (the current interval). $p_{1}$ and $p_{2}$ are the resultant ratios for the inactive and active periods respectively.

Based on these assumptions we try to predict the landfalling numbers for each year between 1970 and 2007 to determine which assumption gives the best prediction. 'Best prediction' is defined in this situation as the model that produces the lowest out-of-sample mean squared error (MSE). The errors are shown in Figure 3.

In the first case, the underlying distribution of the number of landfalls is considered constant so the outof-sample hindcast prediction for each year is made by taking the average number of landfalls for all years, except the five consecutive years we are trying to predict, since 1970. The error between this prediction and the actual number of landfalls within those five years is squared and the mean of these squared errors is compared with the MSE of the other predictions.

In the second scenario, we use the fact that there is a constant relationship between the landfalling numbers and the basin numbers to predict the landfalling numbers using the basin information. The prediction is made by first making an out-of-sample estimate of the level of activity in the basin for the appropriate period, and then converting that basin prediction to a landfalling number using the constant relationship between basin and landfalling numbers. The landfalling proportion is calculated out-of-sample from all data since 1970 .

The third scenario assumes that both the landfalling numbers and the proportion of landfalls vary with the changes in the basin numbers. In this case, only the information within each activity period can be used to estimate the level of activity and we have no way of estimating a useful relationship between landfalling numbers and basin numbers. Here, the historical landfalling predictions are made by estimating the out-of-sample mean number of landfalls during each activity period.

In all three cases, we make the assumption that the 1994-1995 change is known when it happens but not before. This means that the predictions for scenarios 2 and 3 that include a shift are based on the activity of the period before the shift. In practice, an abrupt change in activity is difficult to detect even a couple years after it occurs, so this assumption does not fully penalize these
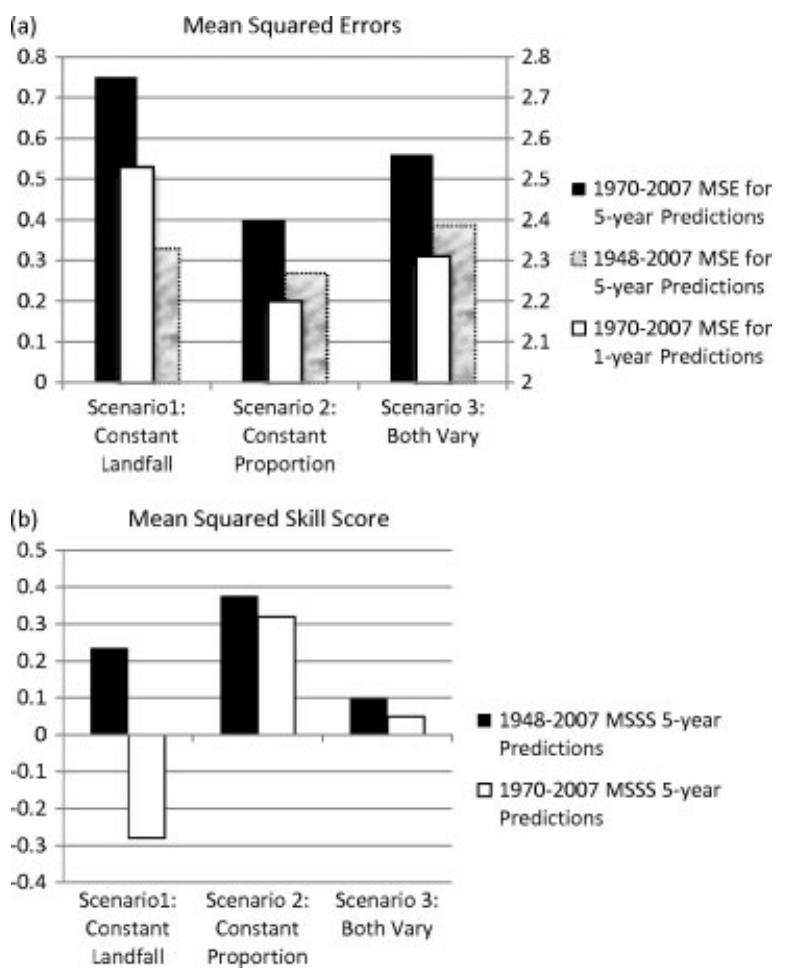

Figure 3. Mean squared errors (MSE) of out-of-sample hindcasts of US landfalling hurricanes. (a) Black and shaded bars denote MSE for 5year predictions and the scale is on the left. The white bars denote MSE for 1-year predictions and the scale is on the right. (b) The mean squared skill score is shown for 5-year predictions for the three scenarios compared with a climatological forecast given by the average landfall rate of the previous 10 years.

methods but does account for some of the error due to the determination of the change points.

Figure 3 shows both the mean squared errors from hindcast tests and the mean squared skill score of the hindcasts compared with a simple climatological prediction. The mean squared skill score is

$$
M S S S=1-\frac{M S E(\text { scenario })}{M S E(\text { climatology })}
$$

which can be interpreted as the percentage improvement of the hindcast compared with a past climatological hindcast. Here we use the mean landfalling hurricane rate for the previous 10 years as the climatological prediction. Not surprisingly, scenarios 2 and 3 perform better than this climatology because the climatological hindcast is not informed of the change points, even after they have occurred. In all cases, however, the largest improvement in skill is when we assume that the proportion is constant, scenario 2. In Figure 3(a) we can see that the second scenario also produces the smallest out-of-sample error for both 5-year and 1-year out-of-sample hindcasts from 1970-2007. This figure also shows the out-of-sample MSE for predictions from 1948 that include both the change point in 1994-1995 and the Jewson and Penzer change point in 1969-1970. Note the large reduction in the error of scenario 1 from the error calculations of the shorter period to the error calculations of the longer period. This is mainly due to the increase in the overall 
landfalling rate (as the period from 1948-1970 has a higher landfalling rate than most of the years since 1970). This increase in the mean landfalling rate reduces some of the larger errors generated during the last active period. This error can be reduced further if we include landfalling information since $1900(\mathrm{MSE}=0.31)$ as the addition of these data also raises the landfalling average. However, even then the qualitative results remain the same, in that the second scenario has the lowest error. This implies that more accurate hindcasts of the past are made by assuming that a constant proportion of basin hurricanes hit the US coast. This assumption allows us to use the information in the basin to make indirect predictions of the landfalling numbers.

However, given the small number of data and the large uncertainties associated with the estimates of both landfall means and proportions, ultimately it make sense to consider forecasts from both methods that use information from the entire basin and methods that use only the landfalling numbers.

\section{Conclusion}

There are two main points made in this article.

(1) Data show that we cannot reject the hypothesis that the proportion of Atlantic hurricanes that make landfall in the USA is constant.

(2) History implies that it is useful to assume that the proportion is constant when making 5-year predictions of the landfalling hurricane rate.

We first consider whether or not the proportion of hurricanes hitting the US coast changes relative to changing activity in the basin. The difference in proportions between change points is tested using chi-square tests on three null hypotheses, as well as by using pairwise tests. The results are consistent, showing that there is a significant difference in the proportions before and after 1948 but the proportions in the second half of the century are not significantly different from one another despite significant changes in the number of Atlantic hurricanes. The change in the middle of the century is likely due to improvements in the observational coverage over the Atlantic, which meant that Atlantic hurricanes that never came close to land were more likely to be observed in the second half of the century. In the second study we ask whether or not we can observe changes in the proportion over any time, without specific comparison with the basin changes. We find that the variability in observed yearly proportions is consistent with the assumption that the underlying proportion is constant. These results, however, seem to contradict previous studies where we test the difference in landfalling numbers over these same periods. In those studies, the landfalling numbers also fail to have significant changes even though we know that the basin numbers do have significant changes. The resolution to this apparent contradiction lies in the sparsity of landfalling hurricanes. Currently, there is not enough data to resolve potential changes in both the landfalling numbers and the proportion. In fact, it is most likely that both the number of landfalls and the proportion are changing to some degree. However, a simple Monte Carlo simulation and a calculation of the signal-to-noise ratios show that signals in the proportions are easier to detect than signals in the landfalling numbers. And finally, since our main interest is in predicting landfalling numbers in the future, we are ultimately interested in knowing which assumption gives us better predictions. Using a simple out-of-sample hindcast framework, we show that by assuming that the proportion is constant we are able to make use of the basin information and make better predictions of the number of hurricanes that hit the US coast.

We use a number of different methods, but the results all agree, and are very clear.

(1) The proportion of hurricanes making landfall in the first half of the 20th century, as estimated from HURDAT data, is different from the proportion in later periods.

(2) The proportion of hurricanes during different periods of activity since 1948, however, shows no evidence of change.

(3) The assumption of a constant proportion leads to more accurate historical predictions of landfalling numbers.

\section{Acknowledgement}

We thank Chris Landsea and Adam Lea for their helpful comments and suggestions.

\section{References}

Bell GD, Blake E, Landsea CW, Chelliah M, Pasch R, Mo KC Goldenberg SB. 2007. The 2006 Atlantic hurricane season: a climate perspective. State of the climate in 2006. Bull. Am. Meteorol. Soc. 88: $1-78$.

Bengtsson L, Hodges KI, Esch M, Keenlyside N, Kornblueh L, Luo J, Yamagata T. 2007. How may tropical cyclones change in a warmer climate? Tellus A 59: 539-561.

Bove MC, O’Brien JJ, Eisner JB, Landsea CW, Niu X et al. 1998. Effect of El Niño on US landfalling hurricanes, revisited. Bull. Am. Meteorol. Soc. 79: 2477-2482.

Box GEP, Hunter WG, Hunter JS. 1978. Statistics for Experimenters; An Introduction to Design, Data Analysis and Model Building. John Wiley: New York.

Camargo SJ, Sobel AH. 2005. Western North Pacific tropical cyclone intensity and ENSO. J. Climate 18: 2996-3006.

DeMaria M, Baik JJ, Kaplan J. 1993. Upper-level angular momentum fluxes and tropical cyclone intensity change. J. Atmos. Sci. 50: $1133-1147$.

Elsner JB, Jagger T, Niu XF et al. 2000. Changes in the rates of North Atlantic major hurricane activity during the 20th century. Geophysical Res. Lett. 27: 1743-1746.

Emanuel KA. 1986. An air-sea interaction theory for tropical cyclones. Part I: Steady-state maintenance. J. Atmos. Sci. 42: 585-606.

Emanuel KA. 1995. Sensitivity of tropical cyclones to surface exchange coefficients and a revised steady-state model incorporating eye dynamics. J. Atmos. Sci. 52: 3969-3976.

Emanuel K, Sundararajan R, Williams J. 2008. Hurricanes and global warming: Results from downscaling IPCC AR4 simulations. Bull. Am. Meteorol. Soc. 89: 347-367. 
Goldenberg SB, Shapiro LJ et al. 1996. Physical mechanisms for the association of El Niño and West African rainfall with Atlantic major hurricane activity. J. Climate 9: 1169.

Goldenberg SB. 2001. The recent increase in Atlantic hurricane activity: causes and implications. Science 293: 474.

Gray WM. 1979. Meteorology over the Tropical Oceans, Shaw DB (ed). Royal Meteorological Society: Bracknell. Pp 155-218.

Gray WM. 1984. Atlantic seasonal hurricane frequency: Part I: El Niño and 30-mb quasi-biennial oscillation influences. Mon. Weather Rev. 112: $1649-1668$.

Hoyos CD, Agudelo PA, Webster PJ, Curry JA. 2006. Deconvolution of the factors contributing to the increase in global hurricane intensity. Science 312: 94-97.

Jarrell JD, Hebert PJ, Mayfield M et al. 1992. Hurricane experience levels of coastal county populations from Texas to Maine, NOAA Technical Memorandum NWS NHC-46. Coral Gables, FL. 154 pp.

Jarvinen BR, Neumann CJ, Davis MAS et al. 1984. A tropical cyclone data tape for the North Atlantic Basin, 1886-1983: Contents, limitations, and uses. NOAA Technical Memorandum NWS NHC 22. Coral Gables, FL. 21 pp.

Jewson S, Penzer J. 2006. An objective change-point analysis of landfalling historical Atlantic hurricane numbers arXiv:physics/0 611071.

Klotzbach PJ. 2006. Trends in global tropical cyclone activity over the past twenty years (1986-2005). Geophys. Res. Lett. 33: L10805. DOI:10.1029/2006GL025881.

Knutson TR, Tuleya RE. 1999. Increased hurricane intensities with $\mathrm{CO}_{2}$-induced warming as simulated using the GFDL hurricane prediction system. Climate Dynamics 15: 503-519.

Knutson TR, Tuleya RE. 2004. Impact of $\mathrm{CO}_{2}$-induced warming on simulated hurricane intensity and precipitation: Sensitivity to the choice of climate model and convective parameterization. J. Climate 17: $3477-3495$
Knutson TR, Sirutis JJ, Garner ST, Vecchi GA, Held IM et al. 2008. Simulated reduction in Atlantic hurricane frequency under twentyfirst-century warming conditions. Nature Geoscience 1: 359-364.

Landsea CW. 1998. The extremely active 1995 Atlantic hurricane season: environmental conditions and verification of seasonal forecasts. Mon. Weather Rev. 126: 1174-1193.

Landsea CW. 2007. Counting Atlantic Tropical Cyclones back to 1900. EOS 88: 197.

Landsea CW, Harper BA, Hoarau K, Knaff JA et al. 2006. Can we detect trends in extreme tropical cyclones? Science 313: 452-454.

Mann ME, Emanuel KA. 2006. Atlantic Hurricane Trends Linked to Climate Change. EOS 87: 233-244.

Nzerem K, Jewson S, Laepple T et al. 2006. Change-point detection in the historical hurricane number time-series: why can't we detect change points at US landfall? arXiv:physics/0611107v1.

Shapiro LJ. 1982. Hurricane climate fluctuations. Part I: Patterns and cycles. Mon. Weather Rev. 110: 1014-1023.

Solow AR, Moore LJ. 2002. Testing for trend in North Atlantic Hurricane activity, 1900-98. J. Climate 15: 3111-3114.

Trenberth KE. 2005. Uncertainty in hurricanes and global warming. Science 308: 1753-1754.

Vecchi GA, Knutson TR, 2008. On estimates of historical North Atlantic tropical cyclone activity. J. Climate 21: 3580-3600.

Vecchi GA, Soden BJ. 2007. Increased tropical Atlantic windshear in model projections of global warming. Geophys. Res. Lett. 34: L08702. DOI:10.1029/2006GL028905.

Webster PJ, Holland GJ, Curry JA, Chang HR. 2005. Changes in tropical cyclone number, duration and intensity in a warming environment. Science 309: 1844-1846.

Zehr RM. 1992. Tropical cyclogenisis in the Western Pacific. NOAA Technical Report NESDIS, 61. NOAA: Washington DC. 